\title{
BONE-CEREBRAL CHANNEL REAMING IN THE TREATMENT OF LIMBS BONE FRACTURES
}

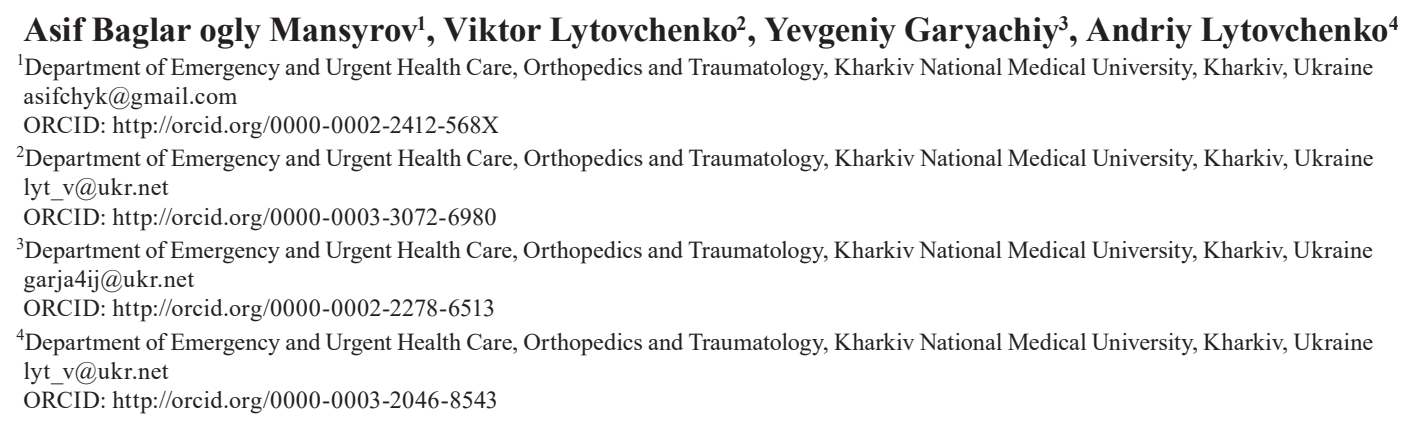

ARTICLE INFO

Article history:

Received date 25.11.2019

Accepted date 28.12.2020

Published date 30.12.2020

Section:

Practical medicine

DOI

10.21303/2313-8416.2020.001559

KE Y W ORDS

diaphyseal fracture

closed intramedullary blocking

osteosynthesis

bone marrow canal

technology

reaming

anatomical and functional results

terms of fusion

quality of life

\section{ABS TR ACT}

The object of the study: clinical effect of intramedullary blocking osteosynthesis of fractures of the bones of the extremities without reaming of the bone marrow canal.

The problem to be solved: determination of the influence of surgical technology of intramedullary blocking osteosynthesis of bone fractures without reaming of the bone marrow canal on the qualitative and anatomical and functional results of treatment.

Main scientific results. The term of fusion of bone fragments in complete groups (including all localizations) in the group of patients who underwent surgery with reaming of the bone marrow canal was $4.21 \pm 0.46$ months, while in the group without reaming of the canal it was much shorter $-3.47 \pm 0.51$ months

Faster functional recovery of the limbs was also observed in cases that precluded bone marrow reaming $-96 \%$ of good and $4 \%$ satisfactory scores were obtained ( $80 \%$ good and $20 \%$ satisfactory in bone marrow reaming).

The technology of closed intramedullary blocking osteosynthesis without reaming of the bone marrow can optimize the time of fusion of bone fragments and get $91 \%$ good and $9 \%$ satisfactory results. Its effectiveness is to reduce the number of satisfactory treatment results by $19 \%$, the absence of unsatisfactory and increase the share of good results by $23 \%$. The area of practical use of research results: clinics of traumatological profile of different levels, in which surgical treatment of fractures of the bones of the extremities are done. An innovative technological product: technology of closed intramedullary blocking osteosynthesis without reaming of the bone marrow canal.

The area of application of an innovative technological product: clinical practice of using the technology of closed intramedullary blocking osteosynthesis without reaming of the bone marrow canal.

(C) The Author(s) 2020. This is an open access article under the CC BY license http://creativecommons.org/licenses/by/4.0).

\section{Introduction}

\section{1. Object of the study}

The object of the study is the clinical effect of intramedullary blocking osteosynthesis of fractures of the bones of the extremities without reaming of the bone marrow canal.

\section{2. Problem formulation}

The method of osteosynthesis and the timing of its implementation are crucial for fracture consolidation. Early stable osteosynthesis prevents further damage by soft tissue bone fragments and the progression of local and systemic inflammatory reactions, creates optimal conditions for reparative osteogenesis and improves the anatomical and functional results of fracture treatment [1].

The philosophy of surgical treatment using intramedullary osteosynthesis with blocking involves sTable fixation of bone fragments in an anatomically correct position without interfering with the fracture area, the possibility of dosed loads on the operated limb in the postoperative pe- 
riod, performing passive and active movements in adjacent joints without additional joints [2, 3]. The main advantage of this method is its low trauma, as the pin is inserted into the bone marrow canal far from the fracture site, which creates an opportunity not to damage the source of periosteal blood supply, which is important in the process of fracture consolidation [4, 5]. Minimally traumatic and minimally invasive closed-loop technology, minimal extraosseous circulatory disorders, preserved inner layer of periosteum, preserved interfracture hematoma, the possibility of static, compression or dynamic blocking have turned such osteosynthesis into a mechanism for fusion of bone fragments.

The advantages of intramedullary osteosynthesis technology also include early mobilization and the possibility of self-care, lack of discomfort throughout the treatment period, the ability to move independently, reducing the length of stay in a medical institution [6].

However, despite its advantages, the treatment of fractures of long bones of the extremities is often accompanied by a number of complications, of which one of the most severe is reparative. The causes of complications are related to defects in the organization of treatment of patients (incorrect treatment tactics, incorrect choice of osteosynthesis, violation of the recovery regime in the postoperative period, failure of the patient to load the limb according to schedule, etc.) and technical errors associated with the actual operation (trauma, unstable osteosynthesis, incorrect choice of metal structures, insufficient hemostasis, etc.) [7, 8].

The causes of most biological failures are tactical and technical errors in performing osteosynthesis and complications in the early stages after fracture, and the implementation of their action is manifested later in the form of delayed consolidation or impaired fusion of bone fragments $[9,10]$.

\section{3. Probable way to solve the problem}

In their previous published studies, a retrospective analysis of the treatment of 403 patients who underwent intramedullary blocked osteosynthesis of the femur, tibia and humerus types A1-A3, B1-B3 and C2 by AO / ASIF, found that the main cause of reparative complications in the treatment of diaphyseal fractures with blocked rods is reaming of the bone marrow canal, which occurred in $56 \%$ of patients with delayed consolidation of bone fragments, in $48 \%$ of patients with nonunion of bone fragments and in $56.3 \%$ of patients with nonunion of joints and [11].

One of the most debatable issues of intramedullary osteosynthesis is the reaming of the bone marrow canal. On the one hand, channel reaming allows the use of larger diameter nails and thus improve the mechanical properties of the system "bone - implant" [12, 13], on the other - reaming causes ambiguous biological changes in the fracture area and throughout the body (local and general effects) $[14,15]$.

When passing through a flexible drill of the bone marrow canal, it is possible for its particles (areas of bone and bone marrow) to enter the fracture zone - the so-called "primary bone graft". According to Frolke's experimental data, about $24 \%$ of the bone material obtained as a result of channel reaming enters the fracture zone [16]. Some authors have observed the formation of new bone around such particles, and in the products of reaming identified viable bone cells. On the other hand, reaming of the bone marrow canal disrupts the blood supply to the inner cortical layer, which, according to [17], is restored within 8-12 weeks.

Common changes that occur during bone marrow reaming include pulmonary embolism or fat embolism, coagulation disorders associated with fever, and inflammatory reactions. Any tool (needle guide, drill or nail) inserted into the bone marrow canal acts like a piston and pushes the contents of the bone marrow cavity or through the fracture slit into the surrounding tissues or into the venous system [15].

To date, there is no convincing evidence of the advantage of using intramedullary nails without reaming of the bone marrow canal compared with osteosynthesis with its reaming [14]. Some authors note the numerous advantages of closed rod installation with bone marrow reaming [18-20], others, on the contrary, note the optimization of reparative osteogenesis without its reaming [21, 22]. According to [14], the difference in the conditions and quality of fracture healing in blocked intramedullary osteosynthesis with reaming of the bone marrow canal and without it should not be sought in different amounts of damage to the bone marrow cavity, and in different conditions of fixation of fragments at introduction of implants in drilled or an 
intact bone marrow cavity with pronounced individual variability in size and shape along its entire length.

Given the significant contradictions in views on surgical technology in performing intramedullary osteosynthesis with or without reamed nail, this problem can be solved by comparing the results of treatment of victims using both surgical technologies.

The aim of the research - study and analysis of the results of treatment of victims with diaphyseal fractures of the bones of the extremities by closed intramedullary blocking osteosynthesis with reaming of the bone marrow canal and without it.

\section{Materials and methods}

The study was conducted on the basis of the trauma department of the municipal non-profit enterprise of the Kharkiv Regional Council "Regional Clinical Hospital" in Kharkiv from 2013 to 2019. The work was conducted in accordance with the Code of Ethics of the World Medical Association (Declaration of Helsinki) and extract from the minutes issues of ethics and bioethics of Kharkiv National Medical University from October 3, 2018. All patients included in the study gave written informed consent.

Group I (control) - included 50 patients (28 men and 22 women, mean age $41.4 \pm 10.3$ years) with fractures of the femoral shaft, tibia and humerus, who underwent surgery, namely - closed blocking intramedullary osteosynthesis with reaming of the bone marrow canal.

The vast majority of patients received fractures of the tibia - 36 patients (72\%), femur and humerus $-8(16 \%)$ and $6(12 \%)$, respectively. In general, bone injuries were dominated by fractures of type A1 - 27 cases (54\%), B1 - 10 (20\%), B2 - 6 (12\%), A2 - 4 (8\%), the rest fractures of types A3 and B3 - 2 (4\%) and 1 (2\%) cases, respectively. The same trend persisted in specific localizations.

Thus, fractures of the tibia type A1 were found in 21 cases $(58.3 \%$ of all fractures of the tibia), B1 - 7 (19.4\%), A2 - 3 (8.3\%), A3 and B2 - 2 cases (5.6 \% each), B3 - 1 (2.8\%). Femoral fractures of types $\mathrm{A} 1$ and $\mathrm{B} 2$ were in 3 cases $-37.5 \%$ (of all fractures of the femur), the rest - in 2 cases (25\%) - type B1. In 4 cases (50\%) performed a retrograde method of inserting the rod. The most common type of humeral injuries were fractures of type A1 - 3 cases ( $50 \%$ of all fractures of the humerus), the remaining A2, B1 and B2 in one case (16.6\% respectively).

The vast majority, namely 29 patients (58\%), surgery was performed within 1 day after injury. 13 victims (26\%) underwent surgery for $2-10$ days, the rest $-8(16 \%)$ - later than the 10th day.

Group II (main) also included 50 patients ( 31 men and 19 women, mean age $38.1 \pm 10.1$ years) with fractures of the femoral shaft, tibia and humerus, who underwent closed blocking intramedullary osteosynthesis without bone marrow reaming.

The vast majority of patients received fractures of the tibia - 31 patients $(62 \%)$, femur and humerus - $13(26 \%)$ and $6(12 \%)$, respectively. In general, among bone injuries fractures of type A1 prevailed - 27 cases $(54 \%)$, B1 - $9(18 \%)$, A2 - $7(14 \%)$, B $2-4(8 \%)$, the rest - fractures of type A3 - 3 cases $(6 \%)$. A similar trend was observed for specific localizations.

Thus, fractures of the tibia type A1 were in 21 cases $(67.7 \%$ of all fractures of the tibia), B1 7 (22.6\%), A2 - 2 (6.5\%), B2 - 1 case (3.2) \%). Femoral fractures of type A1 were in 5 cases (38.5\% of all fractures of the femur), type A2 - in 3 cases ( $23 \%$ ), types A3 and B2 were in 2 cases $-15.4 \%$, the rest of type B1 - 1 case (7.7\%). There were 2 cases of fractures of the humerus type A2 (33.3\% of all fractures of the humerus), the rest A1, A3, B1 and B2 in one case (16.7\% respectively).

The vast majority, namely 27 patients (54\%), surgery was performed within 1 day after injury. 15 patients $(30 \%)$ underwent surgery within $2-10$ days, the rest $-8(16 \%)$ - later than the $10^{\text {th }}$ day.

All surgeries in patients of both groups were performed under epidural or spinal anesthesia.

Tactics of management of patients in the postoperative period included the appointment of antibacterial, anti-edematous, vascular therapy, thromboprophylaxis and prevention of fat embolism, bandaging of the lower extremities with elastic bandages, the use of compression stockings, physical therapy, physiotherapy.

Orthopedic regimen included bed rest for 1-3 days, use of crutches without or with a dosed load on the operated limb. Subsequently, after discharge from the hospital, the patient was 
dynamically monitored with mandatory X-ray monitoring and appropriate recommendations, depending on the period that has elapsed after osteosynthesis and clinical and radiological signs of fracture fusion.

The results of treatment of patients were evaluated according to the method of anatomical and functional results of treatment of fractures of long bones, proposed by SD Tumen in our modification, and according to the standards of quality assessment of treatment of injuries and diseases of the musculoskeletal system and support, which are set out in the Order of the Ministry of Health of Ukraine № 41 from 30.03.94 “On regulation of orthopedic and trauma care in Ukraine” with changes proposed by A. V. Kalashnikov (2006) [23].

The quality of life of patients was assessed according to the EuroQol - 5D system [23] at different times depending on the location of the fracture. The determined terms made it possible to follow the dynamics of changes in the quality of life of patients during treatment, and the final examination in all groups was carried out in the medium term of consolidation of bone fragments in the victims of the control group. Thus, in the case of a fracture of the femur, the assessment was performed within 1.5, 3 and 5 months, in the case of a fracture of the tibia - in the period of 1, 2.5 and 4 months and in the case of a fracture of the humerus - in the period of 1, 2 and 3 months. surgical intervention (I, II and III evaluation period, respectively).

The digital material obtained during the study was processed using the general-purpose data processing software package Statisica for Windows version 6.0. Significance of differences between groups (comparison of average values for each group) was determined using Student's $t$ test $(t)$. Differences at $p<0.05$ were considered significant.

\section{Results}

The general results of treatment of patients of both clinical groups, evaluated by the method of S.D. Tumyan are following.

In 34 patients of the I clinical group (comparison) the results were evaluated as good, as the sum of points in 21 patients was 12 points, in the rest - (13 patients) - 11 points. The average score was $11.62 \pm 0.49$.

Of the 14 patients whose treatment outcome was assessed as satisfactory, 6 had a score of 9 points, the rest ( 8 patients) - 10 points. The average score was $9.57 \pm 0.49$.

It is noteworthy that in 2 patients the results of treatment by this method were assessed as unsatisfactory, because in both cases the amount was 8 points (average score 8.0) (Table 1).

\section{Table 1}

The results of treatment of diaphyseal fractures of the bones of the extremities, evaluated by the S. D. Tumyan method

\begin{tabular}{|c|c|c|c|c|c|c|c|}
\hline \multirow{3}{*}{ Clinical group } & \multirow{3}{*}{$\begin{array}{c}\text { Number of } \\
\text { patients }\end{array}$} & \multicolumn{6}{|c|}{ Treatment results } \\
\hline & & \multicolumn{2}{|c|}{ good (12-11 points) } & \multicolumn{2}{|c|}{ satisfactory (10-9 points) } & \multicolumn{2}{|c|}{ unsatisfactory ( $\leq 8$ points) } \\
\hline & & abs & $\%$ & abs & $\%$ & abs & $\%$ \\
\hline I (comparison) & 50 & 34 & 68 & 14 & 28 & 2 & 4 \\
\hline II (main) & 50 & 46 & 91 & 4 & 9 & - & - \\
\hline
\end{tabular}

In patients of the II (main) clinical group, the results of treatment are much better. Thus, in 46 patients the result was evaluated as good, as the sum of points in 12 patients was 11 points, in the rest (34 patients) - 12 points. The mean score was $11.74 \pm 0.44$.

Satisfactory results occurred in 4 patients with a mean score of $9.75 \pm 0.43$. At the same time 1 st patient had the sum of 9 points, at the rest ( 3 patients $)-10$ points.

The absence of unsatisfactory treatment results in the second clinical group is noteworthy (Fig. 1).

The results of treatment of diaphyseal fractures of the bones of the extremities, evaluated according to the recommendations of the Ministry of Health of Ukraine, are presented in Table 2.

In the first clinical group, good results were observed in 38 cases, while in 10 patients the sum of points was 15 points, in 12 patients - 14 points, in 9 and in 7 - in 13 and 12 points, respectively. The average score was $13.66 \pm 1.06$ (Table 2). 


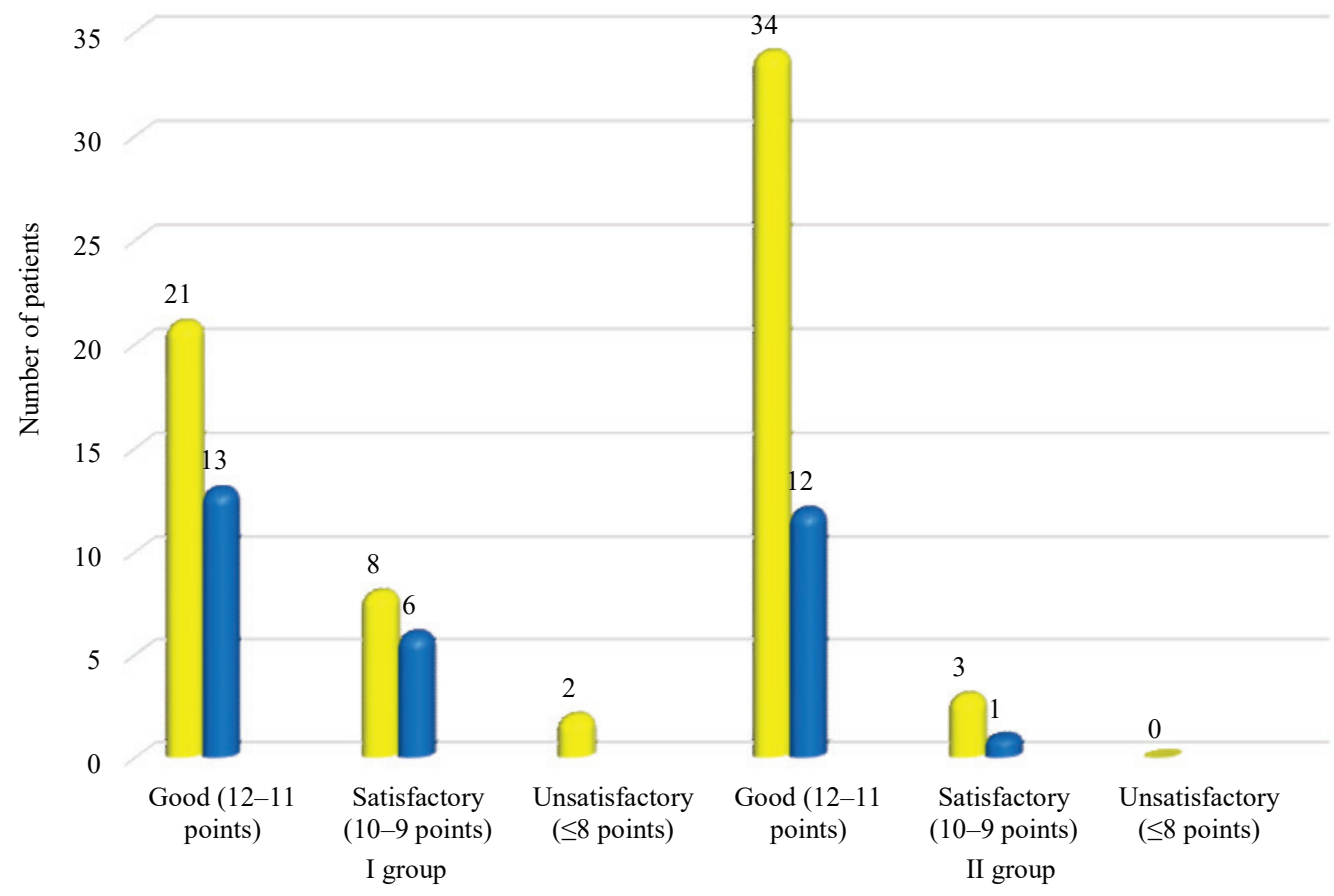

Fig. 1. The results of treatment of victims with fractures of the bones of the extremities, evaluated according to the method of S. D. Tumyan

Table 2

The results of treatment of diaphyseal fractures of the bones of the extremities, evaluated according to the recommendations of the Ministry of Health of Ukraine

\begin{tabular}{|c|c|c|c|c|c|c|c|}
\hline \multirow{3}{*}{ Clinical group } & \multirow{3}{*}{$\begin{array}{c}\text { Number of } \\
\text { patients }\end{array}$} & \multicolumn{6}{|c|}{ Treatment results } \\
\hline & & \multicolumn{2}{|c|}{ good (15-12 points) } & \multicolumn{2}{|c|}{ satisfactory (11-8 points) } & \multicolumn{2}{|c|}{ unsatisfactory ( $\leq 7$ points) } \\
\hline & & abs & $\%$ & abs & $\%$ & abs & $\%$ \\
\hline I (comparison) & 50 & 38 & 76 & 11 & 22 & 1 & 2 \\
\hline II (main) & 50 & 48 & 96 & 2 & 4 & - & - \\
\hline
\end{tabular}

Satisfactory results with the sum of points from 8 to 11 were in 11 patients. 4 patients scored 11 points, 3 patients received 10 and 9 points, 1 patient received 8 points. The average score was $9.91 \pm 1.0$. The results of treatment, assessed as unsatisfactory, were in the 1st patient, the sum of scores was 7.0 .

In the II (main) group of good results there were 48 cases, with the maximum number of points - 15 - found in 14 patients, the sum of 14,13 and 12 points - in 13,11 and 10 patients, respectively. The average score was $13.65 \pm 1.11$.

A satisfactory result took place in 2 cases with a sum of 11 points each. The average score was 11.0. Again, the absence of unsatisfactory results in the second clinical group is noteworthy (Fig. 2).

The average time of consolidation of bone fragments is different in groups, and depended on the chosen surgical technique (Table 3).

Table 3

The average time of consolidation of diaphyseal fractures of long bones of the extremities (months)

\begin{tabular}{|c|c|c|c|}
\hline \multirow{3}{*}{ Clinical group } & \multicolumn{3}{|c|}{ Localization } \\
\hline & thigh & tibia & humerus \\
\hline & \multicolumn{3}{|c|}{ terms of consolidation } \\
\hline I (comparison) & $5.140 .16 \pm$ & $4.10 .5 \pm$ & $3.60 .3 \pm$ \\
\hline II (main) & $4.30 .4 \pm$ & $3.20 .4 \pm$ & $3.10 .2 \pm$ \\
\hline
\end{tabular}

Also evaluated the statistical significance of the difference in terms of consolidation in complete groups (including all localizations). The term of fusion of diaphyseal fractures of the limbs of 
all localizations of the I (control) clinical group was $4.21 \pm 0.46$ months, while in the II (main) group it was much smaller $-3.47 \pm 0.51$ months.

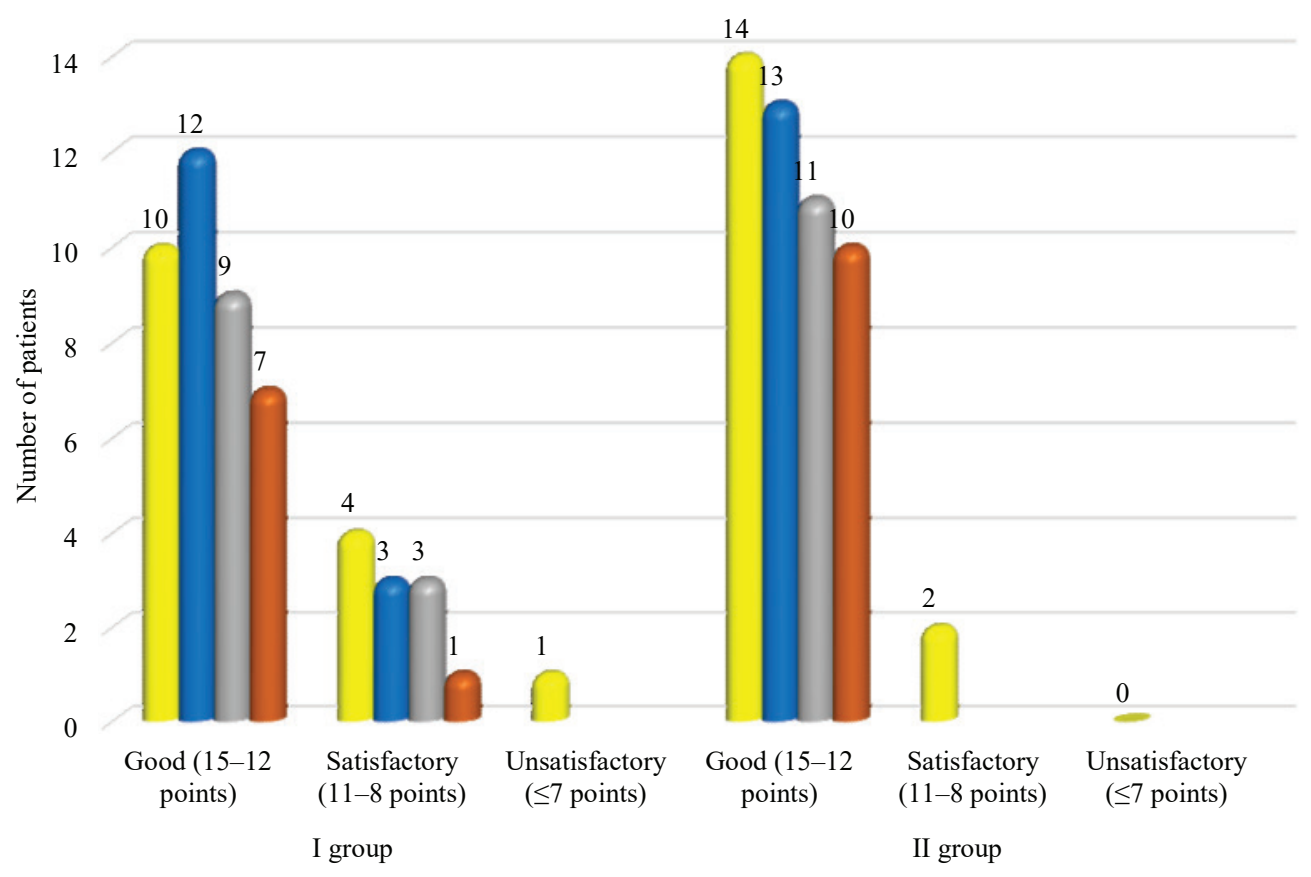

Fig. 2. The results of treatment of patients with fractures of the bones of the extremities, assessed according to the recommendations of the Ministry of Health of Ukraine with changes

The general results of the assessment of the quality of life of patients of both clinical groups according to the EuroQol - 5D system in the first evaluation period are presented in Table 4.

Table 4

The results of the evaluation of the quality of life of patients of both groups according to the EuroQol - 5D system in the first evaluation period

\begin{tabular}{|c|c|c|c|c|c|c|c|}
\hline \multirow{3}{*}{ Clinical group } & \multirow{3}{*}{$\begin{array}{c}\text { Number of } \\
\text { patients }\end{array}$} & \multicolumn{6}{|c|}{ Quality of life } \\
\hline & & \multicolumn{2}{|c|}{ good } & \multicolumn{2}{|c|}{ satisfactory } & \multicolumn{2}{|c|}{ unsatisfactory } \\
\hline & & abs & $\%$ & abs & $\%$ & abs & $\%$ \\
\hline I (comparison) & 50 & 18 & 36 & 27 & 54 & 5 & 10 \\
\hline II (main) & 50 & 19 & 38 & 27 & 54 & 4 & 8 \\
\hline
\end{tabular}

The average score in patients of group I was $2.39 \pm 0.68,4.30 \pm 0.46$ and $6.2 \pm 0.4$ points, respectively, good, satisfactory and unsatisfactory results. Two patients had a score of 1 point, seven had a score of 2 points, and nine patients had a score of 3 points, who rated the treatment results as good. 19 patients who rated the results as satisfactory had a score of 4 points, eight -5 points. Four patients who rated the result as unsatisfactory had a score of 6 points, one patient -7 points.

The same indicator in patients of group II was $2.32 \pm 0.73,4.15 \pm 0.36$ and 6.0 , respectively. Among the good scores, three patients had a score of 1 point, seven had a score of 2, and nine had a score of 3. Satisfactory assessment with the sum of 4 points was 23 patients, 5 points - four. All four patients who rated the results unsatisfactorily had a score of 4 points (Fig. 3 ).

The general results of the assessment of the quality of life of patients of both clinical groups according to the EuroQol - 5D system in the second evaluation period are presented in Table 5.

The average score in patients of group I was $1.97 \pm 1.08,4.21 \pm 0.41$ and 6.0 points, respectively, good, satisfactory and unsatisfactory results. Four patients had a score of 0 points, six had a score of 1 , seven had a score of 2 , and thirteen had a score of 3 , who rated the treatment result as good. Fifteen patients had a satisfactory score with a score of 4 points, and four with a score of 5 points. One patient rated the result as unsatisfactory with a total of 6 points. 


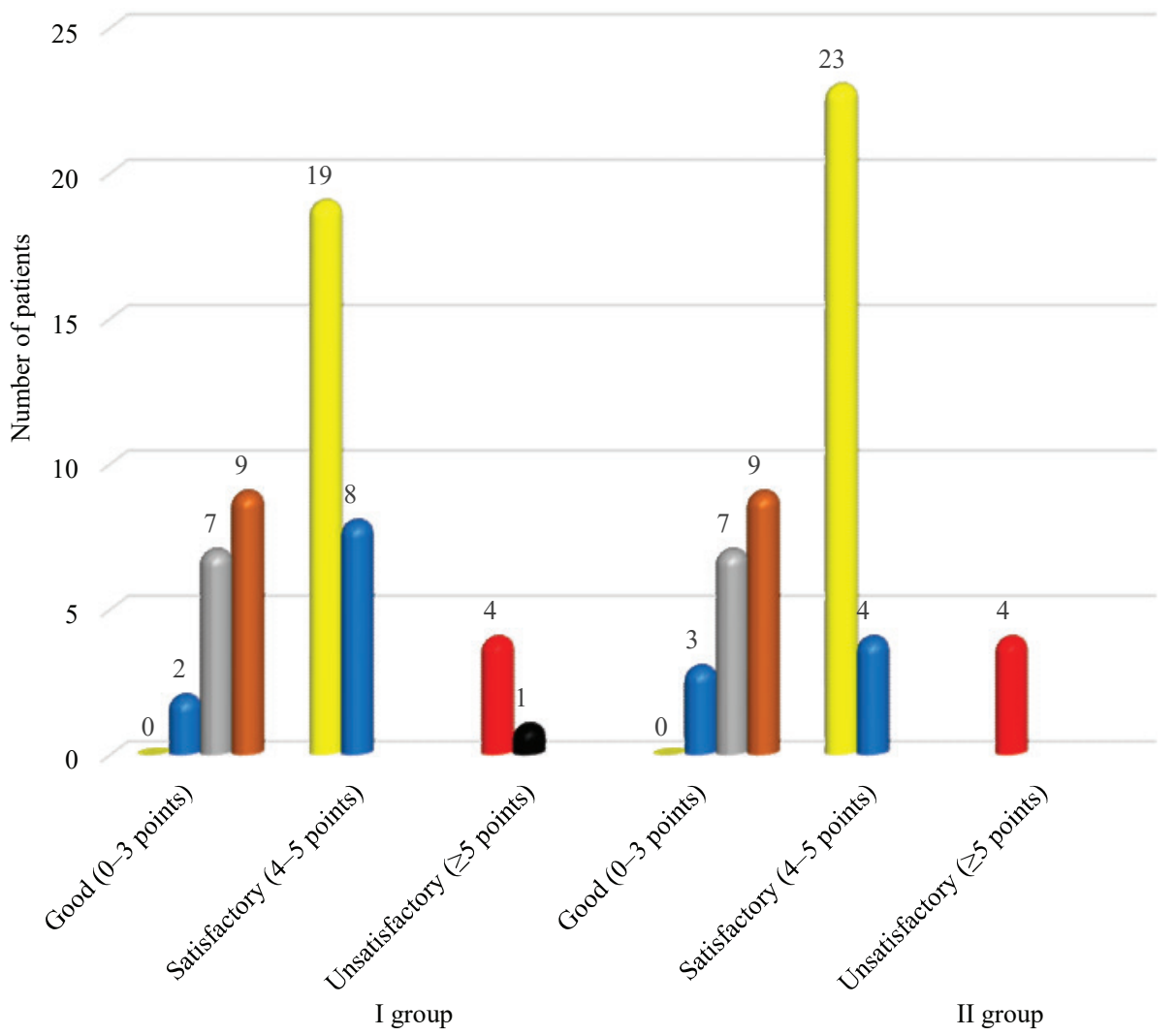

Fig. 3. The results of the evaluation of the quality of life of patients of both groups according to the EuroQol - 5D system in the first evaluation period

Table 5

The results of the assessment of the quality of life of patients of both groups according to the EuroQol - 5D system in the second evaluation period

\begin{tabular}{ccccccccc}
\hline \multirow{2}{*}{ Clinical group } & \multirow{2}{*}{$\begin{array}{c}\text { Number of } \\
\text { patients }\end{array}$} & \multicolumn{3}{c}{ Quality of life } \\
\cline { 3 - 8 } & & & abs & good & satisfactory & \multicolumn{2}{c}{ unsatisfactory } \\
\cline { 3 - 8 } & 50 & 30 & 60 & abs & \% & abs & \% \\
\hline I (comparison) & 50 & 36 & 72 & 19 & 38 & 1 & 2 \\
II (main) & & & & & & 28 & -
\end{tabular}

The indicator of good and satisfactory assessments in patients of group II was $1.72 \pm 1.12$, $4.14 \pm 0.35$, respectively. Among the patients who rated the result as good, the sum of 0 points was seven, 1 point - eight, 2 points - nine and 3 points - twelve patients. Twelve patients had a satisfactory score with a score of 4 points, and two had a score of 5 points (Fig. 4).

Thus, there is not only an increase in the number of patients in group II (by $11.5 \%$ ) who rated the treatment outcome as good, but also the lack of patients who would evaluate the treatment outcome unsatisfactory.

The general results of the assessment of the quality of life of patients of both clinical groups according to the EuroQol - 5D system in the third evaluation period are presented in Table 6.

40 patients of the I (control) group rated the quality of life as good, with the sum of 0 points was observed in six patients, 1 point - in nine, 2 points - in eleven and 3 points - in fourteen patients, respectively. The average score was $1.82 \pm 1.07$.

The quality of life was assessed as satisfactory by 10 patients with a total of 4 points, seven patients and 5 points - three. The average score was $4.3 \pm 0.46$. There were no unsatisfactory results.

The main reasons for the decline in quality of life in patients of clinical group I were difficulties in performing daily work, difficulty during walking and the presence of moderate or severe pain or discomfort. 


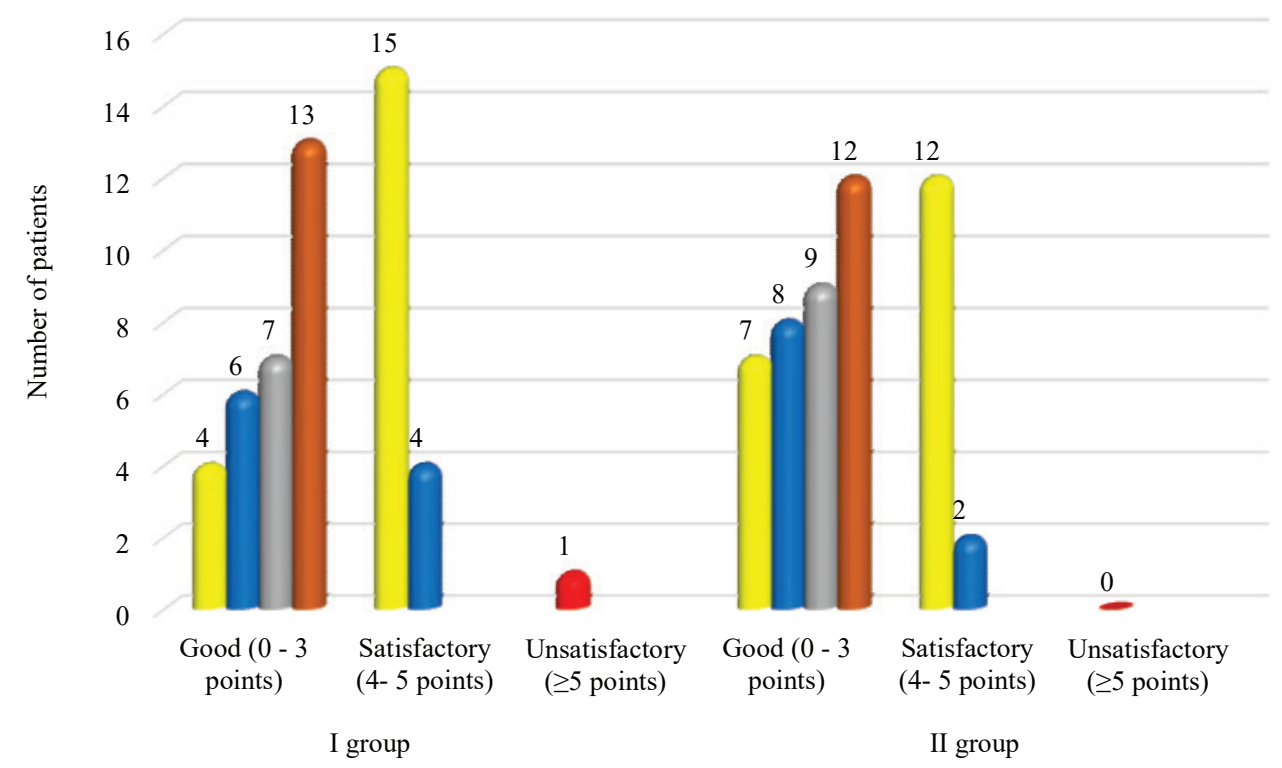

Fig. 4. The results of the assessment of the quality of life of patients of both groups according to the EuroQol $-5 \mathrm{D}$ system in the second evaluation period

Table 6

The results of the evaluation of the quality of life of patients of both groups according to the EuroQol - 5D system in the third evaluation period

\begin{tabular}{|c|c|c|c|c|c|c|c|}
\hline \multirow{3}{*}{ Clinical group } & \multirow{3}{*}{$\begin{array}{c}\text { Number of } \\
\text { patients }\end{array}$} & \multicolumn{6}{|c|}{ Quality of life } \\
\hline & & \multicolumn{2}{|c|}{ good } & \multicolumn{2}{|c|}{ satisfactory } & \multicolumn{2}{|c|}{ unsatisfactory } \\
\hline & & abs & $\%$ & abs & $\%$ & abs & $\%$ \\
\hline I (comparison) & 50 & 40 & 80 & 10 & 20 & - & - \\
\hline II (main) & 50 & 48 & 96 & 2 & 4 & - & - \\
\hline
\end{tabular}

In patients of the II (main) clinical group, the results of quality of life assessment are generally much better. Thus, the results of treatment of 48 patients with an average score of $1.71 \pm 1.10$ are considered good (the sum of 0 points was in 9 patients, 1, 2 and 3 points in 11, 13 and 15 patients, respectively).

Only two patients rated the quality of life as satisfactory with an amount of 4 points each, which was due to a depressed state on the background of moderate pain during daily work. There were no unsatisfactory results (Fig. 5).

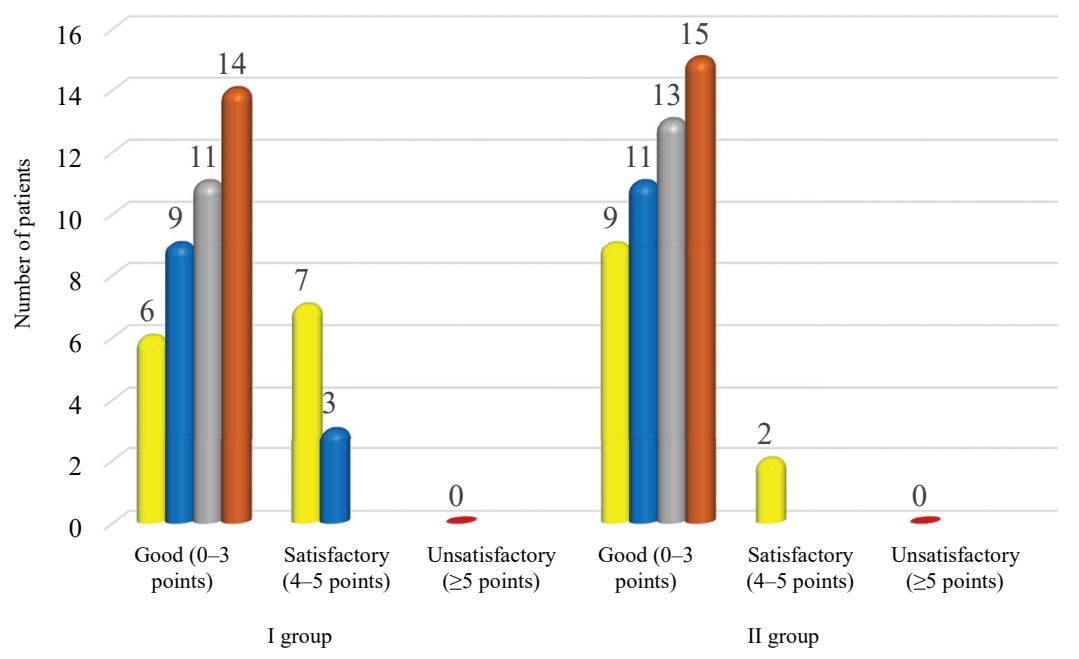

Fig. 5. The results of the evaluation of the quality of life of patients of both groups according to the EuroQol - 5D system in the third evaluation period 


\section{Discussion of research results}

The reason for the satisfactory outcome of treatment of patients of clinical group I was the contracture of adjacent joints and delayed fusion of bone fragments, which was reflected in the evaluation of the results of the two methods used.

It is noteworthy that in 2 patients of group I the results of treatment according to the method of S. D. Tumyan was rated as unsatisfactory because in both cases the sum was 8 points (average score 8.0). In both patients there was a prolongation of the consolidation of bone fragments.

The reason for the satisfactory outcome of treatment of patients of group I, assessed according to the recommendations of the Ministry of Health of Ukraine, as in the previous method, was the contracture of adjacent joints and prolongation of the fusion of bone fragments.

The obtained unsatisfactory results were also due to the prolongation of the consolidation of bone fragments and, as a consequence, the later restoration of the functional capacity of the operated limb.

It should be noted that the evaluation of the results of treatment of diaphyseal bone fractures separately for each anatomical and functional formation makes a system for evaluating the results of treatment by S. D. Tumyan is more critical and detailed.

In group II (main) the reason for the satisfactory results of treatment was the contracture of adjacent joints, which disrupted the function of the limb as a whole.

We believe that the term of fracture consolidation is the most valuable criterion, because it objectively reflects the effectiveness of surgical technology without reaming the bone marrow canal, and also indicates the correctness of the chosen surgical tactics.

The average time of bone fusion indicates their significant reduction with a gentle surgical technique of intramedullary blocking osteosynthesis, namely - without reaming of the bone marrow canal.

The use of surgical technique of closed intramedullary blocking osteosynthesis with reaming of the bone marrow canal in the treatment of diaphyseal fractures of the bones of the extremities (group I) has a chance of a good treatment result $O_{\mathrm{I}}=2,125$.

The use of a similar technique of surgical intervention without reaming of the bone marrow canal increased the chances of a good treatment outcome in patients of group II (main) to $O_{\mathrm{II}}=11.5$.

The chance ratio $(\mathrm{OR})=5.4$, i. e. the chance to get a good result in the II (main) group is 5.4 times higher than the control.

The chance to get a satisfactory result in group I was $O_{\mathrm{I}}=0.47$, in group II it was much lower $-O_{\text {II }}=0.09$. The ratio of chances $(\mathrm{OR})=0.19$, i. e. the chance to get a satisfactory result in the II (main) group in $1 / 0.19=5.2$ times lower than the control.

The risk of obtaining an unsatisfactory result in group I (control) was $R=0.04$, and in group II (main) it is absent.

It is obvious that surgical technology, which differs from the classical one in that before inserting the rod into the bone marrow canal is not drilled, is effective and more appropriate in cases of closed diaphyseal fractures of long limb bones, as it allows to optimize the fusion of bone fragments and restore limb function at an early stage, thereby improving the anatomical and functional results of treatment.

Most authors consider bone marrow reaming as a manipulation that reduces the risk of jamming the rod in the canal or "splitting" the proximal or distal fragments and allows the use of rods of larger diameter, which, in their opinion, leads to more stable fixation of fragments and optimizes biomechanical conditions of stabilization of the segment by the rod, regardless of the existing individual differences in bone structure [12-14]. In addition, proponents of bone marrow reaming indicate an increase in periosteal response and bone marrow effusion, which are key elements of reparative bone regeneration [20].

Another group of researchers, on the contrary, believes that it is not necessary to ream the bone marrow canal, because the stability of fixation of bone fragments is achieved by locking screws and does not depend on tight fit of the rod in the bone marrow canal [15, 21, 22], and minimally invasive implantation of the rod without reaming the canal causes minimal violation of periosteal vascularization, which further contributes to the consolidation of bone tissue [24].

Study limitations. The study was limited by inclusion criteria (closed isolated lesions of the femoral shaft, tibia or humerus types A1, A2, A3, B1, B2, B3 or the same combined lesions with a severity of ISS $<16$ points, which did not significantly affect the course of skeletal injury, age (from 
18 to 60 years) and exclusion (open fractures of the specified localization, closed and open isolated injuries of long bones of extremities of types $\mathrm{C} 1, \mathrm{C} 2, \mathrm{C} 3$, combined injuries of moderate and severe form (ISS $>16$ points), the expressed somatic pathology, neurologic or vascular pathology of the lower extremities).

Prospects for further research. Due to the increased risk of satisfactory and unsatisfactory treatment outcomes in patients whose closed intramedullary blocking osteosynthesis was performed with bone marrow reaming, it is important to further study the impact of this surgical technology, primarily for reparative osteogenesis and the occurrence of reparative complications in the treatment of fractures of long bones of the extremities.

\section{Conclusions}

1. The use of the technology of closed intramedullary blocking osteosynthesis with reaming of the bone marrow canal in the treatment of diaphyseal fractures of the bones of the extremities in patients of group I led to $68 \%$ good, $28 \%$ satisfactory and $4 \%$ unsatisfactory results. The technology of closed intramedullary blocking osteosynthesis without reaming of the bone marrow canal in patients of group II allowed to optimize the time of fusion of bone fragments and get $91 \%$ good and $9 \%$ satisfactory results. The effectiveness of the technology is to reduce the number of satisfactory treatment results by $19 \%$, the absence of unsatisfactory and increase the share of good results by $23 \%$.

2. In the first term of assessment, the quality of life of patients of both clinical groups does not differ from each other. From the second term of assessment in patients of group II functional recovery of the operated limb occurs earlier and in more cases, which is confirmed by $72 \%$ of good and $28 \%$ of satisfactory assessments compared with $60 \%$ of good, $38 \%$ of satisfactory and $2 \%$ of unsatisfactory assessments in patients of group I according to the EuroQol $-5 \mathrm{D}$ system. In the third period, the results of assessments of patients of group II are statistically better than the results obtained in group I $-96 \%$ of good and $4 \%$ of satisfactory assessments and $80 \%$ and $20 \%$, respectively.

3. The clinical effectiveness of surgical technology of closed intramedullary blocking osteosynthesis without reaming of the bone marrow canal, which allows, compared with the control group, significantly increase the chances of a good result $(\mathrm{OR}=5.4)$, reduce the chance of a satisfactory result $(\mathrm{OR}=0.19)$ and avoid unsatisfactory result in the II (main) group.

\section{Conflict of interests}

The authors declare that they have no conflicts of interest.

\section{References}

[1] Nazarov, Kh. N., Linnik, S. A., Musoev, D. S., Mirzoev, R. R. (2016). Frequency, prevention and treatment of false joints in victims with concomitant and multiple lower limb injury (camile). Vestnik Akademii meditsinskikh nauk Tadzhikistana, 4, 63-69.

[2] Glatt, V., Evans, C. H., Tetsworth, K. (2017). A Concert between Biology and Biomechanics: The Influence of the Mechanical Environment on Bone Healing. Frontiers in Physiology, 7. doi: http://doi.org/10.3389/fphys.2016.00678

[3] Rommens, P. M., Kuechle, R., Hofmann, A., Dietz, S.-O. (2018). Repositionstechniken in der Marknagelosteosynthese. Der Unfallchirurg, 122 (2), 95-102. doi: http://doi.org/10.1007/s00113-018-0560-1

[4] Alt, V., Simpson, H., Miclau, T. (2017). Intramedullary nailing - Evolution of treatment. Injury, 48, S1-S2. doi: http://doi.org/ 10.1016/j.injury.2017.04.034

[5] Born, C. T., Pidgeon, T., Taglang, G. (2014). 75 years of contemporary intramedullary nailing. Journal of Orthopaedic Trauma, (28 (8)), 1-2.

[6] Zuev, P. P., Yamshikov, O. N. (2017). Modern trends in intramedullary osteosynthesis of diaphyseal femoral fractures development. Tambov University Reports. Series: Natural and Technical Sciences, 22 (1), 183-186. doi: http://doi.org/10.20310/18100198-2017-22-1-183-186

[7] Hrytsai, N. P., Tsokalo, V. R., Kolov, H. B. et. al. (2015). Septycheskye oslozhnenyia posle khyrurhycheskoho lechenyia perelomov kostei holeny. Visnyk ortopedii, travmatolohii ta protezuvannia, 2 (85), 59-64.

[8] Sultanbaev, T. Zh., Alkhodzhaev, S. S., Tusupov, D. M. (2016). Oshibki oslozhneniia pri lechenii perelomov bedra. Vestnik KazNMU, 3 (1), 315-316.

[9] Sagalovsky, S., Schonert, M. (2014). The cell and molecular biology of bone fracture repair: role of the transforming growth factor- $\beta 1$ in activation reparative osteogenesis (review). Orthopaedics, Traumatology and Prosthetics, 3, 136-143. doi: http:// doi.org/10.15674/0030-598720143136-143 
[10] Mansyrov, A. B. Ogly, Lytovchenko, V., Berezka, M., Garyachiy, Ye., Rami A. F. Almasri (2020). Negative experience in blocking intramedullary osteosynthesis (review). Inter collegas, 7 (2), 81-84.

[11] Mansyrov, A. B., Lytovchenko, V. O., Gariachyi, Y. V. (2020). Complications of Intramedullary Blocking Osteosynthesis of Bones of Limbs and Ways to Prevent Them. Visnyk Ortopedii Travmatologii Protezuvannia, 2 (105), 35-42. doi: http://doi.org/ 10.37647/0132-2486-2020-105-2-35-42

[12] Hrubar, Yu. O., Hariian, S. V. (2010). Interlocking Osteosynthesis By Nails of "Charfix" in Treatment of Diaphyseal Fractures of Long Bones. Shpytalna khirurhiia, 1 (49), 78-80.

[13] Andreichyn, V. V., Bilinskyi, P. I., Neporadnyi, I. D. (2012). Causes of disorders of diaphyseal fractions healing. The modern aspects of stable and functional and intramedular osteosynthesis. Shpytalna khirurhiia, 2, 93-97.

[14] Marchenko, A. C., Fomin, N. F., Moskalev, V. P. (2011). Travmatichnost blokirovannogo intramedulliarnogo osteosinteza v svete topografo-anatomicheskogo n klinicheskogo issledovaniia. Vestnik Rossiiskoi voenno-meditsinskoi akademii, 1 (33), $168-171$.

[15] Sitnik, A. A. (2007). Intramedulliarnii blokiruemii osteosintez dlinnykh trubchatykh kostei. Sovremennii uroven razvitiia / Meditsinskii zhurnal, 4, 22-25.

[16] Frolke, J. P. (2006). Intramedullary Reaming of Long Bones. Practice of Intramedullary Locked Nails. Springer Verlag, $43-56$.

[17] Hodgson, S. (2009). AO Principles of Fracture Management. The Annals of The Royal College of Surgeons of England, 91 (5), 448-449. doi: http://doi.org/10.1308/rcsann.2009.91.5.448b

[18] Fedorov, V. G., Kuzin, I. V., Shapranov, O. N. (2019). Lockable intramedullary osteosynthesis of femur (thigh bone): types of nonunions and false joints. Modern problems of science and education, 6.

[19] Kutsenko, S. N., Mitiunin, D. A., Nikiforov, R. R. (2013). Rol vnutrikostnogo osteosinteza v sisteme khirurgicheskogo lecheniia perelomov kostei goleni i ikh posledstvii: mezhdunarodnii opyt i sobstvennye rezultaty. Litopis travmotologii ta ortopedii, 1-2, 25-26.

[20] Bilinsky, P. I. (2016). On the question of modern osteosynthesis of fractures of the lower extremity. Trauma, 17 (3), 16-17.

[21] Charchian, A. M. (2000). Zakrytii blokiruiuschii intramedulliarnii osteosintez (ZBIO) diafizarnykh perelomov u bolnykh s mnozhestvennoi i sochetannoi travmoi, kak sposob sozdaniia optimalnykh uslovii dlia regeneratsii kostnoi tkani. Novoe $\mathrm{v}$ reshenii aktualnykh problem travmatologii i ortopedii. Sbornik nauchnykh trudov GUN TSITO. Moscow, 78-79.

[22] Charchian, A. M. (2002). Zakritii blokyruiushchyi yntramedulliarni osteosyntez dyafyzarnikh perelomov bedrennoi y bolshebertsovoi kostei bez rassverlyvanyia kostnomozghovoho kanala. Moscow, 102.

[23] Vlasenko, D. V. (2016). Likuvannia polifraktur stehnovoi kistky, Dnipro, 165.

[24] Arshydynov, R. A. (2012). Retrospektyvnii analyz bolnikh, u kotorikh prymenialsia BYOS v lechenyy perelomov nyzhnykh konechnostei. Vestnyk KazNMU, 3, 264-267. 